Revista lus et Praxis, Año 24, No 2, 2018, pp. 431 - 468

ISSN 0717 - 2877

Universidad de Talca - Facultad de Ciencias Jurídicas y Sociales

El ámbito subjetivo de aplicación de la Ley de competencia desleal

Manuel Antonio Bernet Páez

Trabajo recibido el 5 de enero y aprobado el 12 de diciembre de 2017

\title{
El ámbito subjetivo de aplicación de la Ley de competencia desleal
}

\section{The SUbJeCtive SCOPE OF ENFORCEMENT Of the Unfair COMPETITION LAW}

\author{
Manuel Antonio Bernet Páez*
}

\begin{abstract}
RESUMEN
La presente investigación pretende determinar el ámbito subjetivo de aplicación de la Ley de competencia desleal. Al efecto, la Ley No 20.169, de 2007, no reglamenta de manera expresa esta materia, lo cual ha ocasionado una jurisprudencia dispar, siendo particularmente criticable una línea interpretativa estricta que postula que tanto el autor como la víctima de una conducta desleal deben ser empresarios, los cuales deben disputar una misma clientela, exigencia que se denomina relación de competencia. Por el contrario, en este estudio proponemos que el ámbito subjetivo de esta Ley debe ser entendido en términos amplios, puesto que su tutela no se encuentra constreñida sólo a los empresarios competidores, sino a todo aquel agente que participe en el mercado, y cuyos intereses legítimos se vean afectados por un acto de competencia desleal.
\end{abstract}

ABSTRACT

This paper aims to determinate the subjective scope of enforcement of the unfair competition law. Such matter is not expressly regulated in Law No 20.169, of 2007, which it has led to diverse jurisprudence of national courts, being especially reproachable a strict line of legal interpretation that affirms that both author and victim of an unfair act should be entrepreneurs and they must dispute the same costumers, requirement which is named competitive relationship. On the contrary, we propose herein that the subjective scope of this Law must be understand in wide terms, since the protection granted is not limited just to competitors, but to all market players which legitimate interests are affected by an unfair competition act.

Palabras Clave

Derecho comercial, Derecho de la Competencia desleal, Ámbito de aplicación

KEY WORDS

Commercial law, Unfair competition law, Scope of enforcement

\section{Introducción}

El motivo de esta investigación es determinar el ámbito subjetivo de aplicación de la Ley de competencia desleal. Esto es, precisar qué sujetos en su actuar

\footnotetext{
* Profesor de Derecho Comercial, Universidad de los Andes (Santiago, Chile). Doctor en Derecho, Universidad de los Andes. Correo electrónico: mbernet@uandes.cl.
} 
en el mercado quedarán sometidos a las prescripciones de la Ley № 20.169, de 2007. Lo anterior, como enseña la doctrina, es relevante puesto que antes de valorar si una conducta es contraria a esta Ley, de manera previa se debe establecer si las disposiciones de la misma son aplicables tanto al sujeto activo como pasivo del comportamiento que se reprocha como desleal ${ }^{1}$.

En el caso de nuestro país, la Ley de competencia desleal no reglamenta esta materia, lo cual ha ocasionado una jurisprudencia vacilante cuyos resultados son dogmáticamente discutibles. En este sentido, es posible percibir una línea interpretativa restrictiva, conforme a la cual los sujetos amparados por la Ley son exclusivamente los empresarios, y ello en la medida en que quien cometa el acto enjuiciado sea un competidor del legitimado activo, última exigencia que se denomina relación de competencia ${ }^{2}$.

En este punto, es ilustrativa la sentencia pronunciada por el $5^{\circ}$ Juzgado Civil de Santiago recaída en el asunto Monasterio Benedictino de Las Condes con Aguas del Sur y otra, de 2009. En este litigio dicho monasterio imputaba a las demandadas como acto de competencia desleal el uso no consentido del nombre "Benedictino" para distinguir el producto agua natural purificada embotellada, acto que implicaba un aprovechamiento de la reputación de tales monjes, y que inducía a los consumidores a confusión acerca del origen de tales productos. El tribunal rechazó la acción presentada razonando que la actora no es un agente de mercado por su calidad de ente religioso sin fines de lucro, por consiguiente al no ser competidora de las demandadas no se encontraba legitimada para invocar a su favor las normas de la Ley de competencia desleal ${ }^{3}$.

De este modo, como puede advertirse, la respuesta al dilema planteado no es teórica, sino esencialmente práctica, puesto que incide en la estimación de las acciones judiciales intentadas, ya sea por terceros que no son empresarios -como son las entidades sin fines de lucro-, o bien, por legitimados activos que no son competidores del hechor de la conducta examinada ${ }^{4}$.

\footnotetext{
1 MarCo (2009), p. 53.

2 Cabanellas (2015), p. 250.

3 Sentencia de $5^{\circ}$ Juzgado Civil de Santiago, rol № 22094-2007, de 17 de agosto de 2009.

4 A modo referencial, en la sentencia dictada por el $8^{\circ}$ Juzgado Civil de Santiago, rol № 22629-2010, de 8 de julio de 2010, se rechazó una demanda por posible publicidad denigratoria, entre otras razones, por considerar el sentenciador que la Ley de competencia desleal sólo sanciona los actos cuando son cometidos entre competidores, no teniendo tal calidad las partes del proceso a la fecha de la comisión del acto enjuiciado.
} 
Por mi parte, estimo que el ámbito de aplicación de la Ley es más amplio que el sostenido por esta línea hermenéutica estricta, puesto que considero que esta normativa no es sólo aplicable a las contiendas que existan exclusivamente entre empresarios, sino que además, no se debe requerir al legitimado activo que sea competidor del demandado, lo que implica abandonar la exigencia de la relación de competencia.

Para alcanzar esta posición dogmática, en esta exposición inicialmente revisaré el estado de esta cuestión en nuestro Derecho, acto seguido, efectuaré un examen de la misma en algunos de los ordenamientos continentales más representativos, y finalizaré con una postura sobre este asunto debidamente razonada.

\section{El estado de la cuestión en el Derecho chileno}

En cuanto al ámbito subjetivo de aplicación de la Ley de competencia desleal, en sus normas no se dispone de una identificación precisa de qué calidad debe ostentar el autor y la víctima de una conducta que se someterá al escrutinio de deslealtad. Asimismo, tampoco la Ley hace referencia expresa en su articulado a la relación de competencia como un requisito de aplicación de sus disposiciones.

Acerca de lo dicho, creo conveniente revisar si es posible responder a este interrogante acudiendo a la historia fidedigna de la Ley, a la opinión de los autores y a la jurisprudencia sobre la materia.

\subsection{Historia fidedigna de la Ley $N^{0} \mathbf{2 0 . 1 6 9}$}

A modo de recuerdo, se debe mencionar que la Ley $N^{\circ} 20.169$ es fruto de una moción de un conjunto de Diputados. En dicha iniciativa legal, en lo que dice relación a los sujetos sometidos a sus prescripciones, se indicaba en su artículo $1^{\circ}$ que por su intermedio se sancionaban los actos de competencia desleal cometidos por cualquier agente que operase en el mercado nacional ${ }^{5}$. De esta manera, en un primer momento, el ámbito de aplicación subjetivo de la Ley no se limitada a los empresarios, prefiriéndose una denominación neutra como "agente".

Con posterioridad, se sustituyó el texto del artículo $1^{\circ}$ mediante una indicación, que restringió dicho sentido, al señalar que la Ley tendría por objeto sancionar los actos de competencia desleal realizados por cualquier agente

\footnotetext{
${ }_{5}^{5}$ Proyecto de ley para regular la competencia desleal, 8 de marzo de 2006, Boletín № 3.356-03, p. 1.
} 
que opere en el mercado, en calidad de prestador de servicios o de productor, distribuidor o proveedor de bienes. Por consiguiente, a través de esta indicación se pretendía evitar que los consumidores fuesen considerados como un "agente", y por ello sometidos al escrutinio de la Ley 6 .

Acto seguido, con el devenir de la tramitación legislativa se reemplazó de manera íntegra el artículo $1^{\circ}$ por el precepto actualmente vigente ${ }^{7}$. El motivo de esta modificación, en palabras de los autores de la indicación, obedece a que el artículo $1^{\circ}$, como norma introductoria, debe limitarse a enunciar las personas protegidas por sus disposiciones, dando cuenta que su tutela no sólo se reduce a los competidores, sino que también por su intermedio se cautelan los consumidores y de manera refleja la libre competencia ${ }^{8}$.

De esta manera, a primera vista, nuestro legislador prefirió no determinar qué cualidad debe revestir el autor del acto desleal. Esta eventual omisión se recrudece debido a que tampoco en la historia fidedigna de la Ley existen antecedentes definitorios que permitan clarificar si debe existir un vínculo competitivo entre el sujeto que ejecuta la conducta y aquel que la sufre. En este sentido, en algunos pasajes de dicha historia es posible rastrear ciertos indicios que permitirían sostener que la relación de competencia no es requerida ${ }^{9}$, mientras que en otros facultarían allegar a una posición contraria ${ }^{10}$.

${ }^{6}$ Primer Informe de la Comisión de Economía, Fomento y de Desarrollo de la Cámara de Diputados, recaído en el proyecto de ley, en primer trámite constitucional, sobre competencia desleal, 15 de junio de 2005, Boletín № 3.356-03, pp. 26-27.

7 El artículo $1^{\circ}$ de la Ley № 20.169 prescribe: “Esta ley tiene por objeto proteger a competidores, consumidores $y$, en general, a cualquier persona afectada en sus intereses legítimos por un acto de competencia desleal.".

${ }^{8}$ Segundo Informe de la Comisión de Economía del Senado, recaído en el proyecto de ley, en segundo trámite constitucional, sobre competencia desleal, 8 de marzo de 2006, Boletín № 3.356-03, pp. 2-3.

9 Ilustrativa de lo dicho es la opinión expresada por los autores de una indicación que dio origen al vigente artículo $1^{\circ}$, que sobre este punto afirmaron: “(...) existe un consenso actualmente en el derecho comparado en el sentido que los protegidos por las leyes que sancionan la competencia desleal no son sólo los competidores.", en Segundo Informe de la Comisión de Economía del Senado, recaído en el proyecto de ley, en segundo trámite constitucional, sobre competencia desleal,8 de marzo de 2006, Boletín №3.356-03, p. 3

${ }^{10}$ Demostrativa de esta dirección dogmática es la opinión de los autores de la indicación que sirvió de génesis al vigente artículo $3^{\circ}$ de la Ley, que al referirse a la exigencia de que el acto de competencia desleal tenga por propósito desviar la clientela de un tercero, mencionan que: "En todos los principales sistemas jurídicos se ha tendido a sancionar no sólo los actos que tienden a desviar ilícitamente clientela ajena, sino también aquéllos que persiguen aprovecharse indebidamente de la reputación ajena (denominadas "conductas parasitarias»), aunque el tercero víctima no sea un competidor del autor del ilícito (por ejemplo, si una conocida marca de baterías es utilizada por un fabricante de automóviles). Sin embargo, pareciera que estas hipótesis se encuentran suficientemente cubiertas en el derecho nacional por las normas protectoras de la propiedad industrial y, residualmente, por las 


\subsection{El estado actual en la jurisprudencia}

En cuanto a las decisiones judiciales, tanto de aquellas emanadas de tribunales inferiores como de superiores, todavía no es posible apreciar una línea concluyente sobre la determinación del ámbito subjetivo de aplicación de la Ley.

Así, en primer término, respecto a la calidad que debe poseer el hechor del acto desleal, se aprecia una vocación de universalidad por parte de nuestros jueces, ya que no se ha requerido que el sujeto autor del acto sea un empresario o un comerciante, pudiendo apreciarse distintas sentencias en que el legitimado pasivo carece de tal cualificación, siendo sólo lo relevante que ejecute una conducta encuadrable dentro de los términos de la Ley. En este sentido, son destacables las sentencias en que se enjuicia el comportamiento de una extrabajadora de una empresa de corretaje de propiedades ${ }^{11}$, un estudio de $\operatorname{abogados}^{12}$, o el autor de una obra literaria ${ }^{13}$.

En un segundo lugar, con relación a la exigencia de una relación de competencia entre las partes en conflicto, se divisa un cierto desorden dogmático, puesto que es posible distinguir sentencias que demandan tal requerimiento, mientras que otras lo rechazan de manera absoluta.

Así, es demostrativa de esta primera posición la sentencia dictada por el $11^{\circ}$ Juzgado Civil de Santiago, en el litigio Laboratorios Garden House ("Garden House") con Heriberto Madrid Maulén Comercializadora EIRL ("Heriberto EIRL") y otra ${ }^{14}$. En este caso, Garden House atribuía a los demandados Heriberto EIRL y a Apícola y Comercial Gasson Ltda. ("Apícola Gasson") el acto de competencia desleal consistente en la publicidad engañosa respecto del producto "Osteoartrit", el cual el primero de los demandados distribuía en el mercado, y el segundo fabricaba. De esta manera, el tribunal acogió la demanda respecto de Heriberto EIRL, mientras que rechazó la misma respecto de Apícola Gasson, razonando al respecto lo siguiente: "Cuarto: (...) Del bloque normativo reseñado es posible concluir que para estar frente a una hipótesis de competencia desleal

normas de la responsabilidad civil.", en Segundo Informe de la Comisión de Economía del Senado, recaído en el proyecto de ley, en segundo trámite constitucional, sobre competencia desleal, 8 de marzo de 2006, Boletín № 3.356-03, p. 11.

11 Sentencia del $22^{\circ}$ Juzgado Civil de Santiago, rol № 4224-2011, de 25 de octubre de 2012.

12 Sentencia del $24^{\circ}$ Juzgado Civil de Santiago, rol № 1660-2012, de 29 de enero de 2015.

13 Sentencia del $26^{\circ}$ Juzgado Civil de Santiago, rol № 3266-2008, de 15 de junio de 2009.

${ }^{14}$ Sentencia del $11^{\circ}$ Juzgado Civil de Santiago, rol № 11201-2009, de 26 de junio de 2015. Siguen esta misma corriente interpretativa: sentencia del $22^{\circ}$ Juzgado Civil de Santiago, rol № 15271-2010, de 25 de febrero de 2015, sentencia de la Corte de Apelaciones de Concepción, rol № 547-2014, de 16 de abril de 2015; sentencia de la Corte de Apelaciones de Santiago, rol № 7334-2013, de 29 de julio de 2014; sentencia de la Corte Suprema, rol № 8120-2010, de 7 de diciembre de 2012. 
ha de concurrir un elemento esencial, cual es la concurrencia a un mercado de manera horizontal, es decir, que se trate de sujetos que interactúan y concurran en un mercado específico, pues es justamente esa la única forma en que pueda ocurrir la desviación de clientela, cual es finalmente lo protegido por las figuras descritas por la ley. En otras palabras, que se trate de partícipes que realicen actividades económicas similares, en el mismo nivel y que tiendan a satisfacer requerimientos o necesidades de un mismo grupo de clientes. A consecuencia de lo anterior es que Apícola y Colmenares Gasson Limitada no puede ser sujeto pasivo de la acción ejercida toda vez que dicha empresa no participa en la venta al público del producto que produce, por lo cual malamente puede desviar clientela, en el mercado en tanto es que finalmente produce el producto.".

Por consiguiente, según esta primera línea interpretativa la relación de competencia es un requisito indispensable para estimar una acción judicial fundada en la Ley $N^{\circ} 20.169$, concibiéndose dicho vínculo de manera estricta, puesto que los sujetos involucrados en el litigio deben concurrir a un mismo mercado, y con ello deben disputar una idéntica clientela, de forma que la disminución de ganancias de la víctima tiene por causa directa el acto desleal del hechor competidor.

Por otro lado, una posición diversa es posible apreciar en otro cúmulo de sentencias judiciales pronunciadas por los tribunales inferiores y superiores, las que rechazan como exigencia la relación de competencia ${ }^{15}$. Así, es ilustrativa al respecto la sentencia pronunciada por el $19^{\circ}$ Juzgado Civil de Santiago en el asunto Columbia Sportswear Company ("Columbia") con Comercial Windsor Ltda. ("Windsor"). En este litigio la actora Columbia imputaba a Windsor el acto desleal de confusión, debido a que la demandada utilizaba su marca Columbia para distinguir sus productos sin su consentimiento. Por el contrario, para Windsor no podía tener lugar un acto de competencia desleal en la especie, puesto que las partes no eran competidoras entre sí como exige el artículo $3^{\circ}$ de la Ley, destacando que ella comercializaba artículos (ropa de cama) de un rubro muy distinto a los de la demandante (indumentaria deportiva). El tribunal rechazó esta excepción de falta de legitimación pasiva, razonando de la siguiente manera:"(...) Que a mayor abundamiento, el hecho que las partes se dediquen a la producción y comercialización de artículos diversos, de conformidad a la clasificación internacional para las marcas, hace efectivamente que ambas en estricto rigor no sean competidoras, sin embargo, el hecho de encontrarse un artículo avalado por una marca induce a que el cliente o destinatario final

15 Sentencia de $30^{\circ}$ Juzgado Civil de Santiago, rol № 12225-2010, de 14 de marzo de 2012; sentencia de la Corte de Apelaciones de Santiago, rol № 3112-2012, de 16 de diciembre de 2013; sentencia de la Corte Suprema, rol № 23680-2014, de 25 de noviembre de 2015. 
del producto incurra en un error toda vez que asocia una marca determinada a un signo, y éstos a su vez a un prestigio, ignorando de forma completa y total respecto de qué productos tiene cada dueño su marca inscrita y por ende permitido su uso.".

Por tanto, de esta postura reseñada se denota una mirada del Derecho de la competencia desleal alejada de la relación de competencia, la cual se asienta particularmente en la finalidad de esta normativa expresada en su artículo $1^{\circ}$ de la Ley, la que no se enfoca exclusivamente en tutelar el interés de los competidores, sino también se resguarda a los consumidores, los que en el caso reseñado se podrían haber confundido como resultado de la imitación del signo distintivo denunciada.

\subsection{La opinión de los autores}

En la doctrina tampoco se aprecia un panorama pacífico sobre la cuestión examinada, pudiendo distinguirse posiciones contrapuestas. Así, es representativo de una mirada estricta Tapia, al sostener que la Ley de competencia desleal al seguir la lógica de la responsabilidad civil, dispensa una tutela sólo al competidor perjudicado, daño que según su opinión equivale a la disminución de clientela ${ }^{16}$.

En una vereda opuesta, Contreras indica que en virtud del artículo $1^{\circ}$ de la Ley sus disposiciones son aplicables a todo agente concurrente al mercado, y no se exige, como presupuesto para el ejercicio de la acción, que la víctima sea competidora directa del agente desleal. Para dicho autor, la Ley deja atrás el concepto de competencia como aquella relación directa entre el empresario y su víctima, para ampliar su amparo a favor del mercado y la colectividad ${ }^{17}$.

\subsection{Recapitulación}

A modo de síntesis, es posible observar que tanto en la jurisprudencia como en la dogmática no existe una opinión común acerca de la delimitación del ámbito subjetivo de aplicación de la Ley de competencia desleal, extremo que es de interés, debido a que determina en muchas ocasiones la estimación o el rechazo de la acción deducida. A partir de este escenario confuso, considero relevante en las siguientes líneas revisar qué se ha dicho sobre esta cuestión

\footnotetext{
16 TAPIA (2007), pp. 86-88. Este mismo autor en otro texto explica que el ámbito de la competencia desleal se limita a las relaciones horizontales, estas son aquellas que tienen lugar entre agentes que compiten en un mismo mercado. Sobre estas ideas: TAPIA (2008), p. 3. En un similar sentido: CORRAL (2013), p. 331.

17 Contreras (2012), pp. 98-99. En este mismo sentido: Reveco y Padilla (2014), pp. 358-359.
} 
en el Derecho comparado, puesto que sus directrices hermenéuticas me serán útiles para formular una propuesta propia al final de este texto.

\section{El estado de la cuestión en el Derecho comparado}

En miras a realizar un examen a este asunto en el Derecho comparado, he elegido dos sistemas jurídicos continentales que abordan esta cuestión de manera diametralmente opuesta, y que por ello nos pueden iluminar en la indagación iniciada. Así, en un primer momento revisaré el Derecho de la competencia desleal italiano, el cual se caracteriza por no contener una norma legal que determina su ámbito subjetivo, lo cual ha dado pie a una discusión dogmática muy intensa. Luego, en una segunda etapa, pasaré revista a esta materia en el Derecho español, en cuya Ley de competencia desleal se indica con precisión a qué sujetos les son aplicables sus normas, circunstancia que no ha impedido el surgimiento de disputas judiciales acerca de este extremo.

\subsection{El ámbito subjetivo en el Derecho de la competencia desleal italiano}

La norma básica que reglamenta la competencia desleal en Italia es el artículo 2598 del Código Civil, en virtud de la cual se castiga como un ilícito civil ciertos actos de competencia desleal especialmente descritos -como los actos de confusión-, y que contiene una cláusula general de competencia desleal, según la cual se debe sancionar aquel que se vale de un medio contrario a los principios de corrección profesional (correttezza professionale) idóneo para dañar el establecimiento (azienda) de otro.

A partir de esta norma, la jurisprudencia y la doctrina han interpretado de manera mayoritaria que son condiciones necesarias de toda acción de competencia desleal que (i) el sujeto activo y pasivo de la acción sean empresarios, y (ii) que entre éstos debe existir una relación de competencia (rapporto di concorrenza $)^{18}$. Por la importancia de esta materia, se realizará un examen separado, primero de los sujetos de la acción, y en segundo lugar, de la relación de competencia.

\section{a) Los sujetos de la acción de competencia desleal}

Como he indicado, existe una opinión común respecto de que las partes de un litigio de competencia desleal deben ostentar la calidad de empresarios. Así, en cuanto a la exigencia de que el hechor de la conducta sea un empresario, se sostiene que tal calificación se debe a que el acto de competencia desleal

18 Ubertazzi (2007), p. 2071; Signorini (2014), p. 116. 
supone que quien lo cometa concurre al mismo mercado de la víctima, infringiéndole un daño a su azienda, perjuicio que se identifica con la sustracción de su clientela ${ }^{19}$. Asimismo, se señala que la cláusula general, al mencionar como criterio de valoración de la conducta enjuiciada la rectitud profesional, evidencia que sólo pueden estar obligados a respetar tal estándar aquellos sujetos que realizan una actividad económica como empresa ${ }^{20}$.

Respecto a la víctima, se argumenta que también debe tener la condición de empresario. Tal posición se cimenta esencialmente en argumentos literales, puesto que se ha interpretado que el concepto de azienda contenido en el artículo 2598 del Código Civil debe entenderse como empresa, la cual está definida en el artículo 2083 del mismo Código, y que se concibe como el ejercicio profesional de una actividad económica organizada para los fines de la producción o el intercambio de bienes o de servicios ${ }^{21}$. Además, se esgrime que el Derecho de la competencia desleal, por los remedios procesales que concede, es una tutela privilegiada, que sólo se justifica si el beneficiario de la misma es un empresario, y que la ejerce en contra de otro sujeto de su misma condición, en un plano de reciprocidad ${ }^{22}$.

Sin perjuicio de lo dicho, se debe prevenir que importantes autores han criticado severamente esta posición doctrinal ${ }^{23}$. Así, una primera apreciación negativa se refiere a que al exigir que los sujetos implicados sean empresarios, quedarían al margen de las normas sobre competencia desleal los profesionales liberales, no existiendo ninguna justificación dogmática para ello, puesto que se trata de actividades de suyo asimilables a las empresariales ${ }^{24}$. En segundo término, se reprueba la tesis predominante debido a que por su intermedio podrían quedar sin sanción aquellos actos que afectan severamente a los distintos agentes del mercado, sólo por la particularidad de que su hechor no es empresario $^{25}$. Por último, se sostiene que la competencia desleal no es una tutela

\footnotetext{
19 LiberTini (2016), pp. 288-290.

20 GHIDINI(1991), p. 42.

21 Guglielmetti (1970), p. 51.

22 Ascarelli (1970), p. 167.

23 Se debe mencionar que dentro de esta doctrina minoritaria existen distintas posiciones sobre la materia, que van desde sostener que cualquier persona puede ser autor de un acto de competencia desleal, como afirmar que el sujeto activo del acto escrutado debe ser un empresario, aunque no es necesario que el mismo sea competidor de la víctima. Acerca de estas distintas opiniones doctrinales: SCIRÉ (1989), pp. 90-117.

24 Jaeger (1971), p. 189; Guglielmetti (1970), p. 70; Florida (2012), p. 338.

25 Sobre lo dicho, se razona que conforme a la doctrina mayoritaria no se podrían castigar los actos desleales cometidos por interpósita persona, o bien, por entidades sin fines de lucro, como puede
} 
privilegiada exclusivamente a favor de los empresarios o, en otras palabras, un Derecho de la clase empresarial. Por el contrario, en la actualidad se considera que esta rama jurídica no tiene por propósito proteger posiciones individuales de ciertos agentes, sino pretender la tutela de diversos intereses colectivos, en particular los consumidores, quienes también gozarían de legitimación activa ${ }^{26}$.

Por último, a pesar de que la posición dogmática mayoritaria puede ser estimada restrictiva, es preciso apuntar que de manera paulatina la jurisprudencia ha ido ampliando la noción de empresario, no limitándose sólo a aquel sujeto de derecho privado que realiza actividades mercantiles en forma organizada. De este modo, se ha encasillado dentro de esta categoría al ente público en cuanto realiza actividades económicas, al concesionario de un servicio público, al emprendedor agrícola, al empresario que carece de azienda porque todavía no ha iniciado sus actividades, y una sociedad que se encuentra en una fase de liquidación ${ }^{27}$.

\section{b) La relación de competencia}

El segundo requisito examinado por los jueces en toda acción de competencia desleal es que exista una relación de competencia entre las partes, la cual tiene lugar cuando dos sujetos ofrecen los mismos productos o servicios en el mercado, los que están destinados a satisfacer idénticas o similares necesidades, de forma que ambos empresarios disputarían una misma clientela ${ }^{28}$. Frente a la ausencia de esta exigencia, el comportamiento reprochado no podrá ser enjuiciado conforme a las normas especiales del ilícito desleal, debiendo por ello someterse a las normas generales del ilícito aquiliano establecido en el artículo 2043 del Código ${ }^{29}$.

Para la doctrina y jurisprudencia mayoritaria, este requerimiento de la acción de competencia desleal se infiere de argumentos de texto ${ }^{30}$, como también de

ser una asociación en defensa de la naturaleza que realiza una campaña denigratoria respecto de un producto. Sobre lo dicho, vid.: LiBERTINI (2016), pp. 290-291.

${ }^{26}$ Auletta (1973), p.176.

27 GHIDINI (2001), pp. 9-13.

${ }^{28}$ Vanzetti Y di Cataldo (2005), p. 11.

${ }^{29}$ Rovelu (1967), p. 8.

${ }^{30}$ Los fundamentos literales de esta posición son: (i) los ilícitos especialmente descritos en sus numerales $1^{\circ}$ y $2^{\circ}$ del artículo 2598 del Código Civil limitan su protección exclusivamente a los competidores; (ii) el artículo 2598 del Código Civil se ubica bajo el capítulo intitulado "De la disciplina de la competencia", y (iii) la cláusula general contenida en el mismo artículo 2598, al mencionar como criterio de valoración de la conducta la rectitud profesional, supone que tal estándar es sólo exigible entre competidores empresarios. Sobre lo dicho: SCHRICKER (1968), pp. 28-29. 
la configuración misma del ilícito desleal. Sobre lo último, se sostiene que el daño concurrencial sólo puede consistir en un desvío de la clientela que sufre la víctima, perjuicio que sólo tendrá lugar si el hechor de la conducta es su competidor $^{31}$.

La admisión de este canon en el Derecho italiano no ha estado exenta de críticas. Es así que algunos autores han sostenido que esta regla por su estrechez adolece de deficiencias, ya que permitía dejar impune comportamientos desleales en que no hay una identidad entre los productos implicados, o no hay una coincidencia temporal o geográfica entre los empresarios involucrados ${ }^{32}$.

Frente a estos reparos, los tribunales han incorporado distintas reglas tendientes a suavizar la rigidez del requisito de relación de competencia. Así, un primer elemento hermenéutico que se ensayó fue sustituir la estrecha regla acerca que las partes implicadas debían comercializar un idéntico tipo de producto o servicio (criterio objetivo), por otra consistente en considerar si los litigantes proveían bienes o servicios que satisfacían una semejante necesidad a los consumidores (criterio subjetivo) ${ }^{33}$. De esta manera, a partir de este examen más dúctil, se reconocía una relación de competencia entre un bar y un cine situados en una misma calle, o entre una empresa que fabrica y vende cosméticos y una compañía periodística, que seleccionaba y publicaba recomendaciones de artículos femeninos, entre ellos, cosméticos ${ }^{34}$.

Acto seguido, la jurisprudencia consideró que no era necesario que las partes realizaran sus actividades comerciales en una misma fase empresarial, bastando sólo alegar una competencia próxima entre ellas debido a que compartían una misma categoría de consumidores finales ${ }^{35}$. A partir de esta noción, empezaron a admitirse pretensiones intentadas por sujetos que se encontraban en diversos niveles de la cadena de comercialización de los productos, puesto que se comprendió que habría este vínculo de competencia si el comportamiento del demandado incidía en ciertos clientes finales que eran comunes a las partes, lo que usualmente ocurre entre el fabricante y los minoristas ${ }^{36}$.

Finalmente, frente a la exigencia rígida de la tesis tradicional acerca de que las partes debían compartir una exacta clientela, los jueces idearon la noción de competencia potencial, según la cual el actor sólo debía probar en el proceso,

\footnotetext{
31 Ghidini (1991), pp. 58-59.

32 Vanzetti y di Cataldo (2005), p. 12.

33 SCIRÉ (1989), p. 166.

${ }^{34}$ Font (1986), pp. 252-253.

35 Auterl, (1990), p. 350.

${ }^{36}$ GHIDINI (1991), pp. 71-72.
} 
que ya sea en términos espaciales, temporales o del producto, probablemente en el futuro sería competidor del demandado ${ }^{37}$. De este modo, si de las circunstancias del caso, se podía deducir que el demandante se encontraba en una fase de expansión al mercado geográfico en que operaba el demandado, o que estaba en sus planes confeccionar productos análogos a los ofrecidos por el mismo, entonces los tribunales daban por cumplido el requisito de relación de competencia, lo que permitía inclusive sancionar aquellos comportamientos parasitarios que se caracterizan por la ausencia de una clientela común ${ }^{38}$.

Por otro lado, a pesar de las elasticidades interpretativas incorporadas por los jueces al requisito de relación de competencia, es preciso mencionar la opinión de destacados autores que postulan su eliminación como un elemento propio de la acción de competencia desleal ${ }^{39}$. Así, según esta doctrina el examen de los tribunales debe ceñirse sólo en determinar si se está en presencia de una conducta prohibida, siendo irrelevante en tal análisis precisar si los sujetos implicados son competidores. Esta posición se cimenta, en primer término, en que no es ajustado el parecer común que identificaba el daño concurrencial exclusivamente con la desviación de clientela, en atención a que existen una serie de actos desleales $-v$. gr. la captación de empleados, el espionaje industrial o el boicot- en que dicho perjuicio no se percibe. En un segundo lugar, se argumenta que esta visión reduccionista de la disciplina de la competencia desleal le niega todo valor a la calidad concurrencial que debe imperar en los mercados ${ }^{40}$.

En síntesis, en el Derecho italiano la relación de competencia se mantiene como un requisito propio de la acción de competencia desleal. Sin embargo, su interpretación más rígida ha ido matizándose por la jurisprudencia, de forma que se admiten acciones judiciales en que no se percibe una clientela común entre las partes, ya sea debido a que se encuentran situadas en distintos niveles del proceso de comercialización, o bien son meramente competidoras potenciales.

\subsection{El ámbito subjetivo en el Derecho de la competencia desleal español}

Como he advertido anteriormente, la Ley de competencia desleal española reglamenta de manera específica el ámbito subjetivo de aplicación de la

\footnotetext{
37 LiBERTINI (2016), p. 295.

38 Ubertazzi (2007), p. 2073; Vanzetti y di Cataldo (2005), p. 13.

39 Libertini (2016), pp. 294-296; SANTAGata (1975), pp. 43-45; Florida (2012), p. 337.

40 Por todos: GHidini (1991), pp. 60-62. A modo de ilustración, este autor se pregunta por qué razón no debe ser castigado como desleal una publicidad denigratoria formulada por un sujeto no competidor, cuando el comportamiento en cuanto tal es el mismo, siendo sólo la diferencia la calidad de concurrente.
} 
misma. Es así que su artículo $3^{\circ}$ establece que dicha Ley será aplicable a los empresarios, profesionales y cualquier persona que participe en el mercado, añadiendo que no se requerirá una relación de competencia entre el sujeto activo y el sujeto pasivo del acto de competencia desleal. Adicionalmente, esta norma se complementa con el artículo 33 de la Ley que regula la legitimación activa, y que en términos generales dispone que gozará de dicha legitimación cualquier persona que participe en el mercado, y cuyos intereses económicos resulten directamente perjudicados o amenazados por una conducta desleal ${ }^{41}$.

De esta manera, es posible apreciar prima facie que en el Derecho español -a diferencia del Derecho italiano- la competencia desleal aparece como una disciplina desvinculada del empresario, tanto en lo que respecta al sujeto activo como pasivo del acto desleal. No obstante lo dicho, estimo relevante realizar un examen más detallado de este Derecho, puesto que a pesar de la claridad de las normas aplicables, ello no ha impedido que surjan ciertas contiendas dogmáticas. De esta manera, se analizará separadamente (i) los sujetos de la acción, y luego (ii) la relación de competencia.

\section{a) Los sujetos de la acción de competencia desleal}

Conforme indica el artículo 3.1. de la Ley, sus disposiciones serán aplicables a todas las personas, sean o no empresarios, que participen en el mercado. Acerca de esta orientación, Massaguer indica que la finalidad de la Ley es que el control de deslealtad alcance a todos los sujetos, de manera que puede hablarse de una desmercantilización de la competencia desleal, siendo aplicable sus normas a empresarios, profesionales liberales, artistas, deportistas, trabajadores y la administración pública ${ }^{42}$.

A partir de esta aproximación, la doctrina se ha mostrado especialmente generosa en la conformación del agente activo de un acto de competencia desleal. Así, para Bercovitz lo determinante no es la naturaleza del autor, sino el contenido y finalidad del acto que se realiza en el mercado, de ahí que queden sometidos a esta Ley incluso aquellas personas que efectúan actos esporádicos y aislados, como ocurre, a modo de ejemplo, con aquel sujeto que ha heredado unas alfombras, y al ponerlas a la venta, engaña al público sobre la procedencia o calidad de las mismas ${ }^{43}$. Acerca de lo mismo, se ha sostenido

\footnotetext{
${ }^{41}$ La vinculación entre ambas normas es destacada por GARCía, al indicar que el artículo $3^{\circ}$ de la Ley dilucida quién puede cometer un acto de competencia desleal, mientras que el artículo 33 fija quién está legitimado para ejercitar las acciones que dispensa la Ley. Esta opinión se encuentra en: GARCíA (2008), p. 60.

42 Massaguer (1999), p. 128.

${ }^{43}$ Bercovitz (2011a),pp. 87-89.
} 
que las disposiciones de la Ley son obligatorias para agrupaciones informales sin personalidad jurídica -clubes de amigos o peñas taurinas-, como también para entidades sin fines de lucro, como son las fundaciones ${ }^{44}$. Por último, se debe dar cuenta que este enfoque ha sido seguido por la jurisprudencia, pudiendo señalarse que se ha enjuiciado el comportamiento realizado por una congregación religiosa administradora de un colegio que infringía una norma que prohíbe vender textos en establecimientos escolares ${ }^{45}$, una persona que se atribuía la calidad de integrante de una conocida agrupación musical para promocionar sus servicios ${ }^{46}$, o una federación deportiva que se publicitaba como un organismo con reconocimiento oficial, circunstancia que no era cierta ${ }^{47}$.

Por otro lado, con relación a la víctima, el artículo 33 de la Ley contempla una legitimación activa ordinaria amplia, puesto que goza de tal calidad toda persona que participe en el mercado, y cuyos intereses económicos resulten directamente perjudicados o amenazados por una conducta desleal ${ }^{48}$. Acerca de esta norma, la doctrina se ha centrado en indagar sus dos requisitos esenciales, estos son, (i) qué se entiende por participar en el mercado, y (ii) en qué casos los intereses económicos de la víctima se ven afectados ${ }^{49}$.

Sobre la exigencia de participación en el mercado, se ha sostenido que la misma es escasamente útil, puesto que tal condición puede predicarse de cualquier persona, ya sea que desarrolle actividades empresariales o profesionales, o bien contrate bienes o servicios ofertados ${ }^{50}$. De este modo, la jurisprudencia ha dicho que participan en el mercado tanto los empresarios como los consumidores de manera individual, destacando además que es participante aquel que actúa de manera esporádica en el mercado ${ }^{51}$, o aquel que concurra sin un

${ }^{44}$ Marco (2009),pp. 46-49.

45 Sentencia del Tribunal Supremo, de 25 de julio de 2007 (RJ 2007, 4705).

46 Sentencia del Tribunal Supremo, de 6 de febrero de 2001 (RJ 2001, 543).

47 Sentencia de la Audiencia Provincial de Madrid, de 4 de junio de 2004 (AC 2004, 1723).

${ }^{48}$ Se debe mencionar que el artículo 33 de la Ley dispone adicionalmente una legitimación activa extraordinaria a favor de los siguientes sujetos: (i) asociaciones o corporaciones económicas, cuando resulten afectados los intereses de sus miembros; (ii) el Instituto Nacional del Consumo y otras corporaciones competentes en materia de defensa de los consumidores; (iii) las asociaciones de consumidores y usuarios; (iv) otras entidades de los Estados miembros de la Comunidad Europea constituidas para la protección de los intereses de los consumidores, y (v) el Ministerio Fiscal en defensa de los intereses generales, colectivos o difusos, de los consumidores y usuarios.

49 Cervera (2014), p. 1889.

50 TATO et al. (2010), p. 421.

51 Sentencia de la Audiencia Provincial de Barcelona, de 4 de julio de 2007 (JUR 2007, 295133). 
ánimo de lucro ${ }^{52}$. En cambio, carece de la calidad de partícipe en el mercado aquel sujeto que a la fecha de la presentación de la demanda ha cesado en su actividad económica o se mantenga inactivo ${ }^{53}$.

A diferencia del requerimiento anterior, se sostiene que mediante el requisito de afectación a los intereses económicos del legitimado activo se busca restringir la cobertura subjetiva de la Ley. Sobre esta exigencia, la doctrina ha propuesto la aplicación de una aproximación de dos pasos, esto es, en primer término se debe indagar si el actor resulta personal e inmediatamente alcanzado por el acto enjuiciado, afectando negativamente su posición o actividad económica, $y$, en segundo lugar, se debe rechazar la tutela de aquellos perjuicios, actuales o eventuales, que se causen a bienes o derechos no protegidos directamente por la Ley de competencia desleal ${ }^{54}$. En este punto los autores recuerdan que, aunque la Ley no requiera una relación de competencia, ello no significa que pueden perseguirse comportamientos que escapan a una finalidad competitiva, sino que descansan en motivos personales o de otra índole, como ocurre, a modo de ejemplo, con la denigración que sufre un empresario relacionada con su vida personal, acción que puede dañar su crédito comercial, pero cuya causa dañosa no es fruto de un acto de competencia ${ }^{55}$.

\section{b) La relación de competencia}

De acuerdo con el artículo 3.2. de la Ley de competencia desleal, su aplicación no puede supeditarse a la existencia de una relación de competencia entre el sujeto activo y el sujeto pasivo del acto de competencia desleal. Acerca del fundamento de esta norma, se afirma que responde a los postulados político-legislativos asumidos en la redacción de la Ley, estos son, la protección institucional de la competencia y no una tutela individual exclusiva a favor de ciertos operadores ${ }^{56}$.

De este modo, la supresión de la relación de competencia, como un requisito propio de la acción de competencia desleal, acarrea importantes consecuencias. Así, se apunta que conlleva el reconocimiento de una legitimación activa amplia, no sólo atribuía a los competidores, sino también a consumidores y a los organismos del Estado. Además, se destaca que la Ley resulta aplicable

\footnotetext{
52 Sentencia de la Audiencia Provincial de Sevilla, de 28 de enero de 1998 (AC 1998, 290).

53 Sentencia de la Audiencia Provincial de Madrid, de 5 de junio de 2006 (AC 2007/277).

54 Massaguer (1997), p. 113.

55 Bacharach de Valera (1993), p. 125.

56 García-Cruces (2014), p. 1164.
} 
inclusive a empresarios monopolistas, que no tienen competidores, pero cuyos actos pueden dañar a consumidores y distorsionar la competencia ${ }^{57}$.

Por su parte, los tribunales de manera general han rechazado cualquier alegación de los demandados acerca de la falta de relación de competencia entre las partes. Sobre ello, como ilustración, en la sentencia dictada por la Audiencia Provincial de Madrid, de 10 de abril de 2001, se condenó a la Real Federación Española de Gimnasia por cometer un acto desleal de confusión, aunque alegará no ser competidora de la actora -que era una empresa fabricante de ropa deportiva-, puesto que actuó como autora del comportamiento enjuiciado consistente en forzar a los gimnastas a colocar una marca en sus vestuarios encima del signo distintivo de titularidad de la demandante ${ }^{58}$.

De esta manera, parecía ser que el Derecho español a través de las normas revisadas ha impedido que surjan discusiones dogmáticas acerca del ámbito de aplicación de la Ley. Tal afirmación, empero, no es enteramente correcta. Ello puesto que la perspectiva impuesta por el legislador de prescindir en su aplicación de los sujetos, en especial de la figura del empresario, ha hecho descansar todo su entramado en el concepto de acto de competencia, la cual trae para algunos la inevitable consecuencia de volver a una noción subjetiva del Derecho de la competencia desleal, debido a que es el empresario es el único autor de tales comportamientos ${ }^{59}$.

Acerca de lo dicho, se considera que el artículo $2^{\circ}$ de la Ley determina los elementos de un acto de competencia, que será aquel que se realice en el mercado y con fines concurrenciales, presumiéndose esto último si el acto, por las circunstancias en que realiza, se revela objetivamente idóneo para promover o asegurar la difusión en el mercado de las prestaciones propias o ajenas.

Sin detenernos en la configuración sobre qué es un acto de competencia -que analizaré más adelante- es preciso destacar que en diversas ocasiones la jurisprudencia española se ha mostrado equívoca en la determinación sobre si un determinado comportamiento es o no un acto de competencia desleal, retornando en muchas ocasiones a aplicar la denominada relación de competencia ${ }^{60}$.

En cuanto a lo afirmado, es esclarecedora la sentencia pronunciada por el Tribunal Supremo en el asunto "Clarín"61. Este litigio fue iniciado por el propietario de un local dedicado a la venta de golosinas, que se ubicaba contiguo

\footnotetext{
57 BerCovitz (2011b), pp. 87-89.

58 Sentencia de la Audiencia Provincial de Madrid, de 10 de abril de 2001 (JUR 2001, 187808).

59 Otero (1991), p. 31.

60 SuÑol (2012), p. 208.

61 Sentencia del Tribunal Supremo, de 15 de abril de 1998 (RJ 1998, 2053).
} 
a un cine, que impugnaba la decisión de este establecimiento de impedir a los espectadores la entrada al mismo con bebidas y comestibles adquiridos fuera de él, debiendo ser comprados tales productos en el bar instalado dentro de sus dependencias. La acción deducida fue rechazada por el Tribunal Supremo, entre otros motivos, por considerar que la prohibición impuesta por el cine no era un acto de competencia, puesto que no estaba destinada a aumentar su cuota de mercado, circunstancia que dependía de si las películas que exhibía tenían o no el favor del público cinéfilo, y no por la calidad de los alimentos que vendía en su interior. Como ha apreciado importante sector de la doctrina, este último razonamiento no es más que una manera encubierta de requerir una relación de competencia, exigencia que conforme al texto expreso de la Ley se encuentra abolida ${ }^{62}$.

En resumen, el Derecho español de la competencia desleal se ha decantado por objetizar esta disciplina, puesto que conforme las prescripciones legales revisadas no interesa la naturaleza del autor del acto desleal, o si tiene una relación competitiva con la víctima. Sin embargo, esta intención del legislador, como hemos revisado, no se logra enteramente, puesto que al resolver qué se debe comprender por acto de competencia -noción sobre el cual descansa la aplicación de la Ley- los tribunales en algunas ocasiones retornan a la mirada subjetiva de la disciplina en estudio.

\subsection{Recapitulación}

A modo de síntesis de este recorrido comparado, se debe mencionar que prima facie el Derecho italiano y el Derecho español han adoptado modelos antagónicos sobre la materia. Es así que el Derecho italiano ha escogido una concepción subjetiva del Derecho de la competencia desleal, puesto que tal disciplina sólo sería aplicable a los empresarios, y en la medida que éstos sean a su vez competidores entre sí. En cambio, el Derecho español se asienta en un modelo objetivo, puesto que sus disposiciones son aplicables a todo sujeto, con independencia de que entre el actor y el demandado exista una relación de competencia. Sin embargo, esta última afirmación debe matizarse, ya que el Derecho español, al despojarse de la figura del empresario, asienta su aplicación en el concepto de acto de competencia, noción que por su propia naturaleza tiene como autor preferente del comportamiento desleal al empresario, de ahí que al menos la perspectiva objetiva propuesta por el legislador hispano se vuelva algo más tenue. Dicho lo anterior, cabe indagar en las siguientes líneas

${ }^{62}$ Costas (1998), pp. 349-366. 
si nuestra Ley se asemeja más al arquetipo subjetivo italiano, o bien al sistema objetivo español.

\section{Una propuesta sobre el ámbito subjetivo de aplicación de la Ley de competencia desleal chilena}

De acuerdo a lo sostenido en la segunda parte de este trabajo, el legislador chileno prefirió omitir qué calidades debían revestir tanto el autor como la víctima de un acto de competencia desleal, como a su vez, si entre ellos debía existir una relación de competencia. Esta omisión, como se ha visto, ha generado discrepancias en la doctrina y la judicatura, de forma que resulta de interés acometer la tarea de precisar cuál es el ámbito subjetivo de la Ley $N^{\circ} 20.169$. Acerca de ello, sólo como un adelanto, a mi parecer nuestro legislador ha seguido de cerca un modelo objetivo, más cercano al español, de ahí la importancia de considerar las opiniones que se han entregado en ese entorno jurídico. Finalmente, a fin de seguir la estructura ocupada en este texto, se revisará primeramente los sujetos de la acción, para luego examinar la denominada relación de competencia.

\subsection{Los sujetos de la acción de competencia desleal}

\section{a) El autor de un acto de competencia desleal}

La primera cuestión que debe resolverse es qué naturaleza debe ostentar el autor de un acto de competencia desleal, esto es, debe ser necesariamente un empresario -como es en el Derecho italiano-, o bien puede ser cualquier persona que participa en el mercado -según el prisma español-. A mi parecer, este interrogante debe ser contestado en términos similares al Derecho hispano, puesto que la figura del agente activo no se restringe únicamente al empresario, dando pie a lo que se denomina la desmercantilización de la competencia desleal.

En este punto, creo que la respuesta a la inquietud planteada se encuentra en una atenta lectura al artículo $3^{\circ}$ de la Ley, que por su importancia reproduciré: "Artículo $3^{\circ}$.- En general, es acto de competencia desleal toda conducta contraria a la buena fe o a las buenas costumbres que, por medios ilegítimos, persiga desviar clientela de un agente del mercado.".

Un primer apunte que debe hacerse a esta norma es que el legislador, al describir qué es un acto de competencia desleal, optó por una mirada objetiva, puesto que no se refirió acerca de la naturaleza del ejecutor de un acto de competencia desleal, siendo sólo lo relevante indagar si efectivamente, por quien sea, se comete tal comportamiento.

Como una segunda anotación, estimo que la clave para descifrar qué características debe tener el autor de una práctica desleal se encuentra en el 
propósito del acto, esto es, desviar clientela de un agente. Ahora bien, existen numerosos comportamientos que son ejecutados por toda clase de personas, que tienen la virtualidad de desviar clientela. Así, a modo de ejemplo, un crítico fílmico podría valorar negativamente una película, o bien una organización no gubernamental podría llamar a boicotear una empresa por el uso de productos químicos en sus alimentos, ambos supuestos que naturalmente podrían producir un desvío de clientela.

Sin embargo, a pesar de que las hipótesis mencionadas poseen la idoneidad para ocasionar el efecto indicado, la doctrina autorizada ha destacado que para el análisis de la conducta el intérprete debe enfocarse en determinar si el comportamiento en cuestión tiene por causa primaria influir en las decisiones de producción y consumo ajenas, o, en palabras de la Ley, perseguir desviar clientela ${ }^{63}$. De este modo, este primer filtro nos permite excluir de la aplicación de la Ley aquellos actos que prima facie no tienen por finalidad alterar las fuerzas en el mercado, como lo son las informaciones periodísticas, el proselitismo político o religioso, o la divulgación científica ${ }^{64}$. Tales comportamientos, aunque puedan originar una desviación de clientela, no deben estar sometidos a la Ley de competencia desleal, ya que se trata de actuaciones valiosas en otras esferas del quehacer humano, que además gozan de una cobertura constitucional ${ }^{65}$.

A continuación, el problema se nos presenta en aquellos supuestos en que el acto enjuiciado envuelve varias finalidades, esto es, no es posible determinar que el único propósito que conlleva el acto es promover algún efecto directo en el mercado, como puede acontecer con un sitio web que primariamente contiene reseñas críticas respecto a las distintas opciones de alojamiento, pero que a la vez permite realizar reservas en los hoteles analizados.

Sobre lo dicho, la doctrina en general se manifiesta renuente a entregar una fórmula universal que de manera infalible precise si una determinada conducta

\footnotetext{
63 Perdices (1999), p. 488.

${ }^{64}$ Acerca de lo mencionado, García indica que el Tribunal Supremo alemán ha resuelto de manera uniforme que ciertos comportamientos, que aunque provoquen efectos en el mercado, no deben estar sometidos a la Ley de competencia desleal, en la medida que sus autores no han tenido la intención de promover sus prestaciones. Así, se da cuenta como ejemplos de este tipo de conductas una campaña de boicot de Greenpeace, un artículo publicado en una revista sobre la inauguración de una firma de abogados, o la crítica culinaria que valoró negativamente un local de vinos. Para mayor profundidad sobre lo dicho: García (2007), p. 12.

${ }^{65}$ Emparanza (2009), p. 33. Sobre lo dicho, Rubí reseña que el Tribunal Constitucional alemán ha denegado la aplicación de la Ley de competencia desleal a supuestos en que se ve implicada la libertad de expresión, como es el caso de la publicación de un libro sobre rankings de abogados especialistas en Derecho de la empresa, al indicar que la posible afectación a la transparencia informativa no es fundamento suficiente para restringir el discurso público. Más información sobre este tópico: RuBí (2005), p. 7.
} 
tiene preferentemente una finalidad competitiva, en particular si en el mismo comportamiento concurren otras orientaciones, cuestión que por tanto debe resolverse de manera casuística ${ }^{66}$.

No obstante ello, es posible adoptar dos directrices que puedan guiar al juez a fijar la finalidad primaria de un acto. La primera, de carácter objetivo, consiste en que se debe atender a la naturaleza del comportamiento enjuiciado, de forma que si su función típica es esencialmente competitiva, esto es, promover productos o servicios en el mercado, entonces quedará sometido a las prescripciones de la Ley. Así, tendrán esta condición los ofrecimientos comerciales y, en general, toda comunicación de una empresa con sus clientes actuales o potenciales, con independencia de cuál sea efectivamente la intención del sujeto ${ }^{67}$. En cambio, si el comportamiento en examen no está ordenado para la consecución de un fin competitivo evidente a favor de su autor, aunque el mismo repercuta en el mercado, deberá quedar fuera del juicio de deslealtad, como ocurre, a modo de ejemplo, con la publicación de un artículo científico que revela los efectos negativos del consumo de un producto o el llamado a huelga de un sindicato que impide al empresario suministrar sus artículos a su clientela ${ }^{68}$.

A su vez, un segundo criterio es el denominado subjetivo, según el cual se debe considerar la naturaleza del sujeto ejecutor del acto, y su actividad principal. De este modo, se estima que todos los actos realizados por una entidad empresarial o profesional tienen una finalidad competitiva, debido a que todo empresario tiene como una vocación innata competir, y su propósito, más o menos disimulado, siempre será la difusión de sus productos o servicios ${ }^{69}$. Ahora bien, como advierten los autores, de esta categoría se deben excluir los medios de comunicación social, los que por su actividad propiamente informativa deben quedar al margen de todo control de deslealtad que podría cercenar el derecho fundamental a la libertad de opinión, a menos que los contenidos emitidos tengan un acusado carácter comercial ${ }^{70}$. Desde un prisma contrario, de acuerdo a esta pauta subjetiva, quedarán exentos del control de deslealtad los actos emanados de personas que no desarrollan actividades propiamente empresariales o profesionales, como lo son las entidades políticas, religiosas o no gubernamentales ${ }^{71}$.

\footnotetext{
${ }^{66}$ SUÑOl (2012), p. 209.

67 Perdices (1996), p. 918.

${ }^{68}$ Massaguer (1999), p. 125.

69 Emparanza (2009), pp. 34-35.

70 SUÑOl (2012), p. 217.

${ }^{71}$ KÖHLER (2011), p. 141.
} 
De esta manera, volviendo al interrogante inicial, estimo que puede ser autor de un acto de competencia desleal toda persona, con independencia de su naturaleza, en la medida en que tal comportamiento persiga desviar clientela, $\mathrm{o}$, en otras palabras, que tal comportamiento tenga por fin influir o alterar las posiciones de que gozan los partícipes en el mercado. Dicho lo anterior, a fin de indagar si el acto en concreto tiene dicha finalidad competitiva, sugiero que el juez debe compatibilizar la aplicación de los criterios objetivos y subjetivos recién revisados.

En concreto, estimo que se podrá presumir que el acto en examen tiene un propósito competitivo si es ejecutado por una empresa o por un profesional, salvo que se pruebe por el demandado que tal conducta, enjuiciada objetivamente, se aleja notablemente de un rol propiamente competitivo, como ocurría con las donaciones carentes de publicidad que realizan las empresas por fines benéficos. Adicionalmente, aquellos actos realizados por otro partícipe en el mercado, como puede ser una asociación de consumidores, debido a que su finalidad institucional se aleja de lo competitivo, se debería presumir que todos sus actos deben quedar fuera de la órbita de la Ley, a menos que se pruebe por la víctima que el agente activo ha actuado al margen de su rol fundacional, o en claro ejercicio abusivo del derecho que lo ampara a afectar de manera indirecta las fuerzas en el mercado, lo que sucederá, por ejemplo, con aquel científico que al publicar un artículo, en vez de criticar un cierto género de productos, derechamente llama a boicotear la adquisición de ciertos artículos de una determinada marca comercial ${ }^{72}$.

Finalmente, se debe mencionar que respecto de los supuestos especiales contenidos en el artículo $4^{\circ}$ de la Ley, de manera reciente la Corte Suprema ha sostenido que esta norma establece una presunción consistente en que todas conductas que descritas en el mencionado artículo son contrarias a la buena fe o a las buenas costumbres y persiguen desviar clientela de un agente del mercado, de manera que basta con acreditar la presencia del tipo específico que se invoca para entender que se está ante un acto de competencia desleal ${ }^{73}$.

\footnotetext{
72 Acerca de lo dicho, se debe tener en consideración la sentencia del Tribunal Supremo español, de 3 de febrero de 2005 (RJ 2005 \1458), que a propósito de un reportaje efectuado por una sociedad de consumidores, señaló que: “(...) la publicación de un artículo informativo, que no es denigratorio, por una sociedad o asociación o cooperativa de consumidores, sobre un bien de consumo, no estaría jamás en el ámbito de la competencia desleal". Por otro lado, de manera correcta, la Audiencia Provincial de Madrid, consideró que debía aplicarse la Ley de competencia desleal a las manifestaciones realizadas por un locutor radiofónico llamando al público a darse de baja en la suscripción de un periódico determinado, puesto que ello se aleja de una función periodística típica. Mayores antecedentes de este último caso en: Auto Audiencia Provincial de Madrid, de 29 mayo de 2007 (JUR 2007\321899).

73 Sentencia de la Corte Suprema, rol № 15897-2015, de 21 de noviembre de 2016.
} 
Como cierre, debemos indicar que nuestra jurisprudencia se ha mostrado particularmente flexible en la determinación de la persona del autor de un acto de competencia desleal, puesto que no lo circunscribe sólo a empresas o comerciantes, sino que también ha enjuiciado comportamientos realizados por personas naturales, como lo son, los trabajadores que crean una empresa que compite directamente con su empleador ${ }^{74}$, o una trabajadora que utilizó la base de datos de su empleadora para desviar clientes a una compañía de su propiedad $^{75}$.

\section{b) La víctima del acto de competencia desleal}

En cuanto a la condición que debe ostentar la víctima, estimo que la Ley № 20.169 sigue nuevamente de cerca el modelo español, en cuanto a que no requiere que la misma sea un empresario, como tampoco ser un competidor del hechor del acto de competencia desleal. En este sentido, el artículo $6^{\circ}$ de la Ley regula la legitimación activa de las acciones de competencia desleal, siendo de particular interés revisar su inciso $1^{\circ}$, que se refiere a la legitimación ordinaria individual en los siguientes términos: "Artículo $6^{\circ}$.- Cualquiera que resulte directa y personalmente amenazado o perjudicado en sus intereses legítimos por un acto de competencia desleal podrá ejercer las acciones señaladas en las letras a) a d) del artículo anterior.".

En cuanto al origen de esta norma, su precedente cercano es el actual artículo 33.1. de la Ley de competencia desleal española, aunque se diferencia en ciertos matices que le otorgan aún una mayor amplitud procesal. En este sentido, de la historia fidedigna de la Ley se debe rescatar que en la redacción primitiva de este precepto se requería que los intereses que se afectasen al legitimado fueron exclusivamente económicos -tal como se dispone en la legislación española-, empero con el devenir del trámite legislativo se sustituyó dicha exigencia por la expresión "intereses legítimos", lo que da pie a dar cobertura a ventajas que pretende el legitimado activo que no sean estrictamente patrimoniales ${ }^{76}$.

Desde un prisma exegético, la primera observación que debe hacerse sobre la norma es acerca de la locución "cualquiera", lo que da cuenta que el afectado por el acto no debe detentar una calidad especial, como ser empresario o competidor, siendo sólo lo relevante que sufra las consecuencias de la conducta desleal, lo cual es coherente con la redacción del artículo $1^{\circ}$ de la Ley, que

\footnotetext{
74 Sentencia de la Corte de Apelaciones de Santiago, rol № 1604-2013, de 30 de mayo de 2014.

75 Sentencia del $22^{\circ}$ Juzgado Civil de Santiago, rol No 4224-2011, de 25 de octubre de 2012.

76 Segundo Informe de la Comisión de Economía del Senado, recaído en el proyecto de ley, en segundo trámite constitucional, sobre competencia desleal, 8 de marzo de 2006, Boletín No 3.356-03, p. 31.
} 
alude que su protección alcanza a "cualquier persona afectada en sus intereses legítimos por un acto de competencia desleal"77.

De este modo, la Ley establece como exigencia procesal respecto de la víctima que (i) sea directa y personalmente amenazada o perjudicada (ii) en sus intereses legítimos por el acto enjuiciado. Acerca del requerimiento de afectación personal y directa, de la historia fidedigna de la Ley se infiere que su imposición obedece a comprender que no se está frente a una acción popular, sino que el demandante debe resultar tocado en su esfera privada por el acto enjuiciado ${ }^{78}$. En una perspectiva similar, BelLido sostiene que la afectación directa debe considerarse como sinónimo de afectación concreta o singular, de forma que la legitimación activa se confiere a aquellos partícipes en el mercado que ostentan un interés concreto, singular, específico, distinto o cualificado respecto del resto de los sujetos, de modo que resulten claras las consecuencias favorables o adversas que se produzcan en la esfera económica o patrimonial del actor en función del resultado de la pretensión interpuesta ${ }^{79}$. De lo anterior, se puede concluir que lo que el legislador requiere es que quien demande resulte alcanzado por la repercusión que el acto de competencia desleal tenga sobre el funcionamiento del mercado, afectando negativamente su posición o actividad, ya sea como un operador profesional o como consumidor ${ }^{80}$.

En cuanto a la exigencia de que los intereses legítimos del actor se vean amenazados o perjudicados por el acto de competencia desleal, se debe indicar en primer término que la expresión "intereses legítimos" debe ser identificada como cualquier ventaja o utilidad que le reporte al demandante la pretensión deducida, no siendo suficiente al respecto un mero interés por el respeto a la legalidad $^{81}$. Luego, siguiendo a BARONA, bajo el concepto de interés legítimo se podría tutelar a todos aquellos que, participando en el mercado, poseen

\footnotetext{
77 Poblete (2007), p. 109. En este mismo sentido, en sentencia de la Corte de Apelaciones de Santiago, rol No 3112-2012, de 16 de diciembre de 2013, se discutía si sólo una competidora de la demandada podía ejercitar la acción, resolviendo la Corte que la Ley no establece tal restricción, puesto que puede ser ejercida por "cualquiera", en la medida que tenga algún nexo con el demandado.

78 Segundo Informe de la Comisión de Economía del Senado, recaído en el proyecto de ley, en segundo trámite constitucional, sobre competencia desleal, 8 de marzo de 2006, Boletín No 3.356-03, p. 31. En una similar línea, en sentencia del $30^{\circ}$ Juzgado Civil de Santiago, rol № 12225-2010, de 14 de marzo de 2012, las partes en conflicto pertenecían a distintos mercados, puesto que la actora era sociedad dedicada al rubro metalúrgico, mientras que la demandada era una empresa de alimentos, empero el tribunal consideró que la demandante tenía legitimación activa puesto que las actividades de las partes se interrelacionaban entre sí, ya que la actora era proveedora de ciertos artículos a favor de la demandada.

79 Bellido (1998), p. 179.

80 Massaguer (1999), p. 562.

81 Muerza(1997), p. 68.
} 
una expectativa de protección frente a una actuación desleal, la cual puede consistir en su cese, su rectificación, e incluso el correspondiente resarcimiento de los daños ocasionados como consecuencia del comportamiento desleal ${ }^{82}$. En segundo lugar, la referencia a un daño actual o futuro que se ocasione por la práctica desleal debe ser interpretada en términos laxos, comprendiendo tanto los posibles perjuicios patrimoniales como morales que pueda sufrir la víctima ${ }^{83}$.

Por lo dicho, se debe concluir que para el legislador nacional lo relevante para atribuir legitimación activa a un sujeto no es poseer una determinada naturaleza, ya sea ser empresario o competidor, sino acreditar tener un interés concreto y específico que se vea perjudicado o amenazado por un acto de competencia desleal, de modo que resulte indudable que el éxito o el fracaso de la pretensión deducida repercutirá en su esfera personal ${ }^{84}$. A partir de lo dicho, a modo de ilustración, resulta evidente que una entidad sin fines de lucro, como lo es la Teletón o Techo-Chile, podría dirigirse en contra de un comerciante por utilizar sus signos distintivos, ya sea registrados o no, en la medida que cause confusión en los consumidores, puesto que sus intereses, ya sea patrimoniales -la pérdida de los ingresos por la falta del pago de la licencia para usar sus logos-como morales -la asociación con productos de mala calidad o vinculados a actividades perniciosas- se verían perjudicados como consecuencia de este acto de competencia desleal.

\section{c) La relación de competencia}

Finalmente, debe resolverse si nuestra Ley requiere para su aplicación que exista una relación de competencia entre el autor y la víctima del acto enjuiciado, no apreciándose un consenso en la jurisprudencia y la doctrina acerca de este extremo. En este sentido, se vislumbra una primera posición que postula que dicha exigencia debe ser requerida, debido a que al demandarse por la Ley que un acto de competencia debe tener por objeto desviar clientela, ello supone que sólo aquel que ha sufrido dicho efecto -el competidor del hechorpuede acudir a los tribunales para obtener la reparación del dicho perjuicio.

\footnotetext{
82 Barona (1999), pp. 232-233.

83 Poblete (2007), p. 110. Sobre lo dicho, se debe mencionar que ya existen algunos pronunciamientos de nuestros tribunales que admiten la reparación del daño moral que sufren las personas jurídicas como resultado de un acto desleal, siendo los más destacados los siguientes: Sentencia del $22^{\circ}$ Juzgado Civil de Santiago, rol No 21140-2014, de 17 de julio de 2015, confirmada por sentencia de la Corte de Apelaciones de Santiago, rol № 10011-2015, de 14 de abril de 2016; y la sentencia del $2^{\circ}$ Juzgado de Curicó, rol No 3564-2011, de 15 de abril de 2014, confirmada por sentencia de la Corte de Apelaciones de Talca, rol No 956-2014, de 11 de noviembre de 2014.
}

84 Bellido (1998), p. 180. 
De este modo, según esta postura, la relación de competencia se impone como un requisito inmanente del artículo $3^{\circ}$ de la Ley de Competencia Desleal. A mi parecer, como veremos a continuación, existirían argumentos atendibles para sostener que la relación de competencia no es una exigencia establecida en la Ley $N^{\circ} 20.169$.

\section{i) La relación de competencia no se ajusta a los objetivos de la Ley}

Así, un primer razonamiento a estimar se refiere a que la relación de competencia resulta ser contradictoria con los objetivos propios de la Ley, los que se expresan en su artículo $1^{\circ}$. En este punto, se debe destacar el legislador concibió el acto de competencia desleal como pluriofensivo, puesto que tiene la aptitud para dañar no sólo a los intereses de los competidores, sino también afectar a los consumidores y a otros sujetos que participan en el mercado. De este modo, el Derecho de la competencia desleal es concebido como un ordenamiento que tutela por igual a los diversos actores en el mercado, y no como disciplina destinada a sólo resolver los conflictos entre los competidores, lo que se denomina "modelo social de competencia".

Por tanto, esta directriz teleológica establecida por el legislador lleva a resolver que la aplicación de la Ley no podrá supeditarse a la existencia de una relación de competencia entre el sujeto activo y el sujeto pasivo del acto de competencia desleal, de lo contrario, se impediría lograr la obtención de los objetivos que el propio legislador se trazó al momento de promulgar la norma ${ }^{85}$. Por otro lado, esta interpretación que se postula es coincidente con la amplia legitimación activa establecida en el artículo $6^{\circ}$ de la Ley, regla que por su contenido resulta incompatible con la demanda de una relación de competencia ${ }^{86}$.

Asimismo, se debe indicar que la posición esgrimida se ajusta de mejor forma a la historia fidedigna de la Ley. Es así que el artículo $1^{\circ}$ de la Ley de competencia desleal fue aprobado en el seno de Comisión Mixta, donde fue objeto de una intensa discusión ${ }^{87}$. En este sentido, el diputado Saffirio y el senador García abogaban por la mantención del artículo $1^{\circ}$ tal como fue aprobado, mientras que el senador Orpis sostenía que el ámbito de la Ley debía circunscribirse a las relaciones horizontales entre los competidores, de forma que presentó una indicación destinada a eliminar del artículo $1^{\circ}$ la frase: "(...) consumidores y,

\footnotetext{
85 García-Cruces (2014), p. 1151.

${ }^{86}$ MARCO (2009), p. 53.

${ }^{87}$ Informe de la Comisión Mixta encargada de proponer la forma y modo de resolver las discrepancias entre el Senado y la Cámara de Diputados respecto del proyecto de ley sobre competencia desleal, 4 de diciembre de 2006, Boletín No 3.356-03, pp. 3-5.
} 
en general, a cualquier persona afectada en sus intereses legítimos por un acto de competencia desleal.". Esta última propuesta no fue finalmente acogida por los demás miembros de la Comisión Mixta, quedando la redacción de la norma conforme el texto vigente que consagra una protección amplia a todos los partícipes en el mercado.

Finalmente, debemos indicar que la Corte Suprema recientemente ha seguido la línea hermenéutica explicada. Es así, que de manera categórica, a modo de obiter dicta afirma: "El objetivo de la ley es proteger a competidores, consumidores $y$, en general, a cualquier persona afectada en sus intereses legítimos por un acto de competencia desleal (artículo $1^{\circ}$ ), lo cual implica que la ley es aplicable a todo agente concurrente en el mercado y no exige como presupuesto para el ejercicio de la acción que la víctima sea competidora directa del agente desleal. Esta opción normativa es vista como una característica que le da una «impronta social», que refleja su interés de brindar protección a la colectividad, formada por todos los agentes del mercado, «de modo de resguardar el interés público que está comprometido en la existencia de una competencia sana y con reglas objetivas de conducta»" 88 .

Con posterioridad, esta corriente interpretativa se confirma con la sentencia de esta misma Corte en el asunto Artel con Dimeiggs, de 2016, en el cual las partes en conflicto no son competidores, pues participan en niveles del mercado distinto. Así, en este juicio, Artel-fabricante de productos oficina y escritoriodemandó a Dimeiggs -distribuidora de dichos artículos- por el acto de competencia desleal consistente en informar engañosamente al Sernac que en sus instalaciones vendía artículos de la marca "Artel" a bajos precios. Luego, con dicha información este servicio publicó una encuesta para el año escolar 2014, en la cual figuraba que la demandada ofrecía los artículos "Artel" a valores muy convenientes. No obstante ello, en el proceso se acreditó que Dimeiggs desde el año 2012 no adquiría mercaderías a Artel, y por tanto se demostró que al proporcionar esos antecedentes falsos al Sernac, lo que se proponía era atraer al público a sus dependencias para ofrecerles productos propios o de terceros, para así incrementar sus ventas ${ }^{89}$.

De este modo, no cabe duda de que el legislador, al establecer como objetivo de la Ley la protección de los intereses legítimos de todos los partícipes en el mercado, abandona la relación de competencia, de ahí que lo relevante será determinar si el acto desleal lesiona, en los términos del artículo $6^{\circ}$ de la Ley,

${ }^{88}$ Sentencia de la Corte Suprema, rol № 23680-2014, de 25 de noviembre de 2015.

${ }^{89}$ Sentencia de la Corte Suprema, rol № 28421-2016, de 12 de julio de 2016. 
a algún agente del mercado, con independencia de que éste sea competidor del infractor.

\section{ii) La Ley de competencia desleal está diseñada como un mecanismo disciplinador de los mercados}

Por otro lado, es preciso mencionar que nuestra Ley de competencia desleal presenta una cualidad muy particular, esta es, ser un instrumento de sanción de los actos desleales que ocurren en el mercado. Acerca de lo dicho, estimo de interés reproducir su artículo 10, inciso $1^{\circ}$, que dice: "Artículo 10.- Si la sentencia firme establece que han existido uno o más actos de competencia desleal, el tribunal que la dictó deberá remitir todos los antecedentes del juicio al Fiscal Nacional Económico, quien tendrá la facultad de referir al Tribunal de Defensa de la Libre Competencia, atendidas la gravedad de la infracción o la extensión del perjuicio provocado, la aplicación de la multa correspondiente de conformidad con esta ley.".

Acerca de esta norma, se debe indicar que la misma fue aprobada en el seno de la Comisión Mixta del Congreso, puesto que existía una persistente discrepancia entre las Cámaras. Es así que la Cámara de Diputados pretendía que, junto con los remedios propios del Derecho privado, el hechor de un acto de competencia desleal debía recibir una sanción de naturaleza administrativa. Por el contrario, el Senado entendió que la competencia desleal era una disciplina que consagraba un ilícito estrictamente civil.

Este debate fue favorable a la posición de los diputados, puesto que se sostuvo en la Comisión Mixta que el Derecho de la competencia desleal cautelaba no sólo intereses privados, sino también públicos ${ }^{90}$. Así las cosas, al consagrarse en el artículo 10 de la Ley este mecanismo represor de las conductas desleales, resulta evidente que la orientación de la misma se aleja de ser un mero régimen destinado a resolver contiendas entre competidores, pasando a ser un Derecho ordenador de todas las conductas en el mercado. Por ello, todo acto desleal debe quedar sometido al castigo de la Ley, con independencia de que quien sufra tal conducta sea a su vez competidor del hechor, puesto que, de lo contrario, no se cumpliría con la satisfacción del interés público de un correcto funcionamiento de los mercados.

90 Informe de la Comisión Mixta encargada de proponer la forma y modo de resolver las discrepancias entre el Senado y la Cámara de Diputados respecto del proyecto de ley sobre competencia desleal, 4 de diciembre de 2006, Boletín № 3.356-03, pp. 7-8. 


\section{iii) Una adecuada interpretación del artículo $3^{\circ}$ de la Ley $^{\circ} 20.169$ no es compatible con la relación de competencia}

Finalmente, cabe hacerse cargo del argumento de texto utilizado por aqueIlos que esgrimen la observancia del requisito de relación de competencia en nuestro Derecho, esto es, que al describir el artículo $3^{\circ}$ de la Ley al acto de competencia desleal como aquel que tiene por propósito "perseguir desviar clientela de un agente del mercado" impone que dicho efecto -la desviación de clientela- sólo ocurrirá si las partes en el litigio son competidores que se disputan una misma clientela, la cual es sustraída por medios ilegítimos a la víctima por el autor del acto.

A mi parecer esta interpretación no es correcta, como trataré de demostrar, puesto que supone una concepción estrecha del daño concurrencial, el cual se identifica como una mera pérdida de clientes por parte de la víctima que han sido usurpados por el autor del comportamiento desleal. En este punto, estimo que tanto por razones de texto como sistemáticas, el legislador, cuando alude a un desvío de clientela, sólo da cuenta de cuál es el fin típico de un acto de competencia, pero en modo alguno pretende imponer como un requisito anexo la relación de competencia.

En cuanto a la argumentación literal, estimo que es relevante dilucidar qué se debe comprender por la expresión "desvío de clientela" utilizada en el artículo $3^{\circ}$ de la Ley. Acerca de ello, lo primero que se debe mencionar es que el sentido natural u obvio de "desviar" es "apartar o alejar a alguien o algo del camino que seguía". Por lo tanto, lo que demanda la norma es que el hechor de la conducta persiga apartar o alejar los clientes de otro, pero en caso alguno requiere que la clientela que se pretende desviarle haya pertenecido al sujeto afectado por el comportamiento enjuiciado ${ }^{91}$. En un segundo lugar, tampoco la norma en examen requiere que la clientela que se pretende desviar por el hechor sea atraída a su favor-comportamiento propio de un competidor-, sino que basta que se persiga entorpecer su senda usual, lo que ocurría, a modo de ejemplo, respecto de aquel fabricante que manifiesta afirmaciones denigratorias

\footnotetext{
${ }^{91}$ Lo dicho se aprecia con nitidez en los casos en que obstruye el ingreso de un agente a un determinado mercado, en los que inclusive todavía no existe una clientela por la cual competir. A modo de ilustración, en la sentencia del $13^{\circ}$ Juzgado Civil de Santiago, rol № 11487-2008, de 11 de agosto de 2009, se consideró como acto de competencia desleal el registro de una marca comercial y el posterior ejercicio de acciones judiciales fundadas en tal título, al acreditarse que tales actos tenían como único propósito que el adjudicatario de un concurso para explotar un nuevo cementerio municipal pudiese dar inicio a la promoción de dicho establecimiento en construcción, destacándose que el hechor de tal conducta ni siquiera postuló a dicha licitación municipal, y por ende sólo obró con la intención de impedir la competencia que tendría lugar con la apertura del nuevo camposanto.
} 
respecto de un distribuidor ${ }^{92}$. En tercer término, la lectura propuesta por los seguidores de la relación de competencia no se condice con la utilización de la expresión "agente del mercado", que es de suyo neutra, y que no se identifica directamente con la naturaleza de "competidor". En este sentido, se debe advertir que si el legislador hubiese querido limitar el acto de competencia desleal entre competidores, fácilmente lo hubiese podido efectuar, tal como lo hizo a propósito del ilícito de inducción al incumplimiento de las obligaciones de un contrato ajeno, el que se contiene en el artículo $4^{\circ}$ letra g) de la Ley ${ }^{93}$.

A partir de lo dicho, en contraste con la tesis que exige que en toda acción de competencia desleal exista una relación de competencia entre los sujetos involucrados, estimo que lo que pretendió el legislador al disponer que el acto de competencia desleal sea una conducta que "persigue desviar clientela de un agente del mercado" es explicitar que el acto que será objeto de enjuiciamiento por la Ley es aquel que tiene por fin influir o alterar las posiciones de que gozan los partícipes en el mercado, con independencia de si entre éstos se mantiene una relación de competencia, lo que he llamado como actos con una finalidad competitiva.

Por otro lado, desde un prisma sistemático, mediante la Ley No 20.416 de 3 de febrero de 2010, se incluyeron dentro del elenco de conductas típicas del artículo $4^{\circ}$ de la Ley $N^{\circ} 20.169$ las letras h) e i), las cuales en términos algo confusos contemplan como supuestos de competencia desleal la explotación de una situación de dependencia económica, comportamiento que considera como sujeto pasivo del mismo a personas -normalmente empresas de menor tamaño dedicadas a la fabricación de productos- que se encuentran en un distinto nivel económico del hechor del acto -que usualmente son empresas que concentran la distribución de los artículos en el mercado- lo que es demostrativo del desapego de la Ley a toda relación de competencia ${ }^{94}$. Tal como enseña

\footnotetext{
92 Sobre lo dicho, AsCARelli expresa que los actos de competencia desleal pueden tener por propósito atraer clientes ajenos, o bien, impedir, directamente o indirectamente, la clientela de terceros, de ahí que no se exige que el acto desleal se caracterice por la finalidad de atraer clientes actualmente ajenos. Esta opinión se encuentra en: AsCARELl (1970), p. 162.

93 Acerca de lo mismo, en la descripción de demás tipos especiales del artículo $4^{\circ}$ no requiere el legislador que el sujeto pasivo de la conducta desleal desplegada deba ser un competidor, prefiriéndose expresiones neutras como "tercero" o "agente de mercado", dando cuenta con ello que sistemáticamente no se exige la relación de competencia para configurar el acto desleal.

94 Sobre los motivos de la incorporación de estos nuevos tipos especiales en la historia fidedigna de la Ley N²0.416 se indica: "Se tipifican dos nuevas conductas en la Ley de Competencia Desleal. La primera de estas conductas es aquélla en que la empresa compradora presiona al proveedor para que le otorgue condiciones similares o mejores a las ofrecidas a su competencia, o no le otorgue a su competencia las mismas condiciones que a ella; y en segundo término, que la empresa compradora incumpla sistemáticamente con las condiciones pactadas con su proveedor.", en Informe de la Comisión
} 
ZABALETA, en la explotación o abuso de una situación de dependencia económica, el comportamiento enjuiciado no tiene lugar en términos horizontales, sino esencialmente verticales, y consiste usualmente en prácticas -como las ventas subordinadas o la imposición de condiciones comerciales discriminatorias-que aplica el gran distribuidor en contra del fabricante, de ahí que se concluye que la exigencia de una relación de competencia entre las partes involucradas es incompatible con la incorporación legal de esta figura en nuestra Ley ${ }^{95}$.

Adicionalmente, estimo que no resulta ajustado identificar como único perjuicio concurrencial que puede ser tutelado por la Ley la pérdida de clientela. En este punto, debo mencionar que -tal como apunta la doctrina italianaexisten diversos actos de competencia desleal en que la merma de clientes no se aprecia, pero no por ello deben quedar impunes. Lo dicho se ilustra con la sentencia dictada por la Corte de Casación francesa en el asunto "Holanda, el otro país del queso", de $1996^{96}$. En este litigio, la oficina holandesa de productos lácteos, titular de la marca "Holanda, el otro país del queso" dedujo una acción en contra de una sociedad dedicada al giro de la venta de flores, por utilizar la fórmula publicitaria "La Costa Azul, el otro país del tulipán". De este modo, reconociendo la Corte la ausencia de una relación de competencia, de todas formas acogió la acción, puesto que estableció que la imitación de esta frase publicitaria constituía una conducta parasitaria que sólo tenía por fin apropiarse del renombre de la marca de la actora.

Como cierre, se debe mencionar que en el Derecho comparado se reconoce especialmente necesaria la protección de los consumidores en el ámbito de la competencia desleal por actuaciones de monopolistas, los cuales quedarían sin cobertura por la exigencia de la relación de competencia, de ahí que debe rechazarse en nuestro ámbito tal exigencia ${ }^{97}$.

\subsection{Recapitulación}

A modo de síntesis, estimo que una correcta lectura sistemática de la Ley № 20.169 permitiría sostener que su ámbito subjetivo de aplicación es amplio, puesto que su tutela no se encuentra constreñida a los competidores. Ahora bien, ello no significa que la figura del empresario o del profesional sea irrelevante para esta Ley, sino que, tal como he esgrimido, usualmente ambos agentes

de Economía del Senado recaído en el proyecto de ley, en segundo trámite constitucional, sobre normas especiales para las empresas de menor tamaño, Boletín, № 5.724-26, 18 de marzo de 2009, p. 25.

95 Zabaleta (2002), pp. 38-41.

${ }_{96}$ Cour de Cassation, Chambre Commerciale, 30 de enero de 1996, № LawLex00573N70CD.

97 KÖHLER (2011), p. 148. 
serán los autores de los actos competitivos desleales, lo cual no obsta que otros partícipes puedan ser enjuiciados si ejecutan un comportamiento con una finalidad primaria concurrencial. En cuanto a la víctima, se ha demostrado que el artículo $6^{\circ}$ de la Ley ha consagrado una legitimación activa generosa, bastando al actor acreditar que su esfera personal se ha visto alcanzado por los efectos perniciosos del acto escrutado. Finalmente, se debe rechazar la exigencia de una relación de competencia entre las partes en conflicto, por ser tal requisito contrario a los objetivos específicos perseguidos por la Ley.

\section{Conclusiones}

a. La Ley de competencia desleal no reglamenta de manera específica su ámbito subjetivo de aplicación. Tal ausencia normativa ha ocasionado una jurisprudencia vacilante cuyos resultados son dogmáticamente discutibles. En particular, es posible percibir una línea interpretativa restrictiva que postula que tanto el autor como la víctima de un acto de competencia desleal deben ser empresarios vinculados por una relación de competencia.

b. Por su parte, en el Derecho comparado examinado en este estudio es posible vislumbrar a primera vista dos acercamientos antagónicos sobre el campo de aplicación de la disciplina de la competencia desleal. Así, el Derecho italiano descansaría en una mirada subjetiva del Derecho de la competencia desleal, de forma que tal ordenamiento regularía la actividad de los empresarios, y en la medida que éstos sean a su vez competidores entre sí. Por su parte, el Derecho español se asienta en un modelo objetivo, siendo sus disposiciones aplicables a todo participe en el mercado, con independencia de que entre el actor y el demandado exista una relación de competencia. Sin embargo, ambos sistemas normativos no son enteramente puros. Así, el Derecho italiano, mediante una labor hermenéutica, ha flexibilizado la noción de empresario, como también la exigencia de una relación de competencia entre los involucrados. Mientras que el Derecho español, aunque gravita sobre el concepto objetivo del acto de competencia, de algún modo en la configuración del mismo tiene en consideración la figura del empresario, por ser éste el autor preferente de esta clase de conducta.

c. Finalmente, se propone que el ámbito subjetivo de la Ley $N^{0} 20.169$ sea interpretado en términos amplios, puesto que su tutela no se encuentra constreñida sólo a los empresarios competidores, sino a todo aquel agente que participe en el mercado, y cuyos intereses legítimos se vean afectados por un acto desleal. De esta manera, siguiendo de cerca el modelo español, lo definitorio no es la naturaleza del autor de la conducta, ni tampoco la calidad que ostenta la víctima para precisar la cobertura de la Ley, sino la comisión de un acto de competencia desleal. En este sentido, lo que se plantea es que el intérprete para 
calificar la legitimación de las partes debe precisar si el sujeto activo ha cometido un acto de competencia desleal y si el sujeto pasivo se ha visto alcanzado por los efectos de tal comportamiento. Por último, para determinar si estamos en presencia de un acto de competencia desleal, resulta de utilidad indagar sobre la finalidad primaria del comportamiento enjuiciado, como también considerar tanto la naturaleza del sujeto ejecutor como su actividad principal.

\section{Bibliografía CitAdA}

Ascarell, Tullio (1970): Teoría de la concurrencia y de los bienes inmateriales, (Traducc. Evelio Verdera y Luis Suárez-Llanos, Barcelona, Studia Albortiana). Auletta, Giuseppe y Manginı, Vito (1973): Delle Invenzione Industriali dei Modelli di Utilita' e dei Disegni Ornamentali della Concorrenza (Bologna, Nicola Zanichelli Editore).

Auterl, Pablo (1990): "La concorrenza sleale", en: Pietro Rescigno, Trattato di diritto privato (Torino, UnioneTipografica - Editrice Torinense), volumen 18, pp. 341-416.

BACHARACH De VAlera, Sol (1993): La acción de cesación para la represión de la competencia desleal (Madrid, Tecnos).

Barona Vilar, Silvia (1999): Competencia Desleal (Doctrina y Jurisprudencia), $2^{a}$ edic. (Valencia, Tirant lo Blanch).

Bellido Penadés, Rafael (1998): La tutela frente a la competencia desleal en el proceso civil (Granada, Comares).

Bercovitz Rodríguez-Cano, Alberto (2011a): "Artículo 2 . Ámbito objetivo", en: Alberto Bercovitz Rodríguez-Cano, Comentarios a la Ley de Competencia Desleal (Cizur Menor, Aranzadi), pp. 79-84.

Bercovitz Rodrícuez-Cano, Alberto (2011b): "Artículo 3․ Ámbito subjetivo", en: Alberto Bercovitz Rodríguez-Cano, Comentarios a la Ley de Competencia Desleal (Cizur Menor, Aranzadi), pp. 85-90.

Cabanellas de las Cuevas, Guillermo et al. (2015):Derecho de la Competencia Desleal (Buenos Aires, Heliasta).

Cervera Martínez, Marta (2014), "Acciones y legitimación ante un acto de competencia desleal. Prescripción", en: José Antonio García-Cruces, Tratado de la Competencia y de la Publicidad (Valencia, Tirant lo Blanch), tomo II, pp. 1843-1942.

CONTRERAS Blanco, Óscar (2012): La competencia desleal y el deber de corrección en la ley chilena (Santiago, Ediciones Universidad Católica de Chile). 
Corral Talciani, Hernán (2013): Lecciones de Responsabilidad Civil Extracontractual, $2^{\mathrm{a}}$ edic. (Santiago, Legal Publishing).

Costas Comesaña, Julio (1998): "El concepto de acto de competencia desleal (Comentario a la Sentencia del Tribunal Supremo de 15 de abril de 1998, en el caso monopolio de las palomitas en los cines)", en: Actas de Derecho Industrial y Derecho de Autor (19, 1998), pp. 349-366.

Emparanza Sobejano, Alberto (2009): "Artículo 2º Ámbito objetivo", en: Fernando Martínez Sanz, Comentario práctico a la Ley de Competencia Desleal (Madrid, Tecnos), pp. 29-38.

FLORIDA, Giorgio (2012): "L'illecito concorrenziale fra il diritto soggettivo e la tutela dei consumatori", en: Paolo Auteri et al., Diritto Industriale, $4^{\mathrm{a}}$ edic, (Torino, G. Giappichelli Editore), pp. 329-346.

Font Galán, Juan Ignacio (1986): "La crisis de la «relación de competencia» como presupuesto de aplicación de la cláusula general de la competencia desleal", en: Revista de la Facultad de Derecho de la Universidad de Complutense (72, 1986), pp. 231-254.

García Pérez, Rafael (2008): Ley de competencia desleal (Cizur Menor, Aranzadi).

García Pérez, Rafael (2007): "El ámbito objetivo de aplicación de la Ley de competencia desleal", en: Revista de Derecho de Negocios (200, 2007), pp. 7-18.

García-Cruces, José Antonio: "Finalidad y ámbito de aplicación de la Ley de Competencia Desleal. La Cláusula General de Deslealtad Competitiva", en: José Antonio García-Cruces, Tratado de la Competencia y de la Publicidad (Valencia, Tirant lo Blanch), tomo II, pp. 1097-1206.

Ghidini, Gustavo (2001): La concorrenza sleale, $3^{a}$ edic. (Torino, Utet).

Guidinı, Gustavo (1991): Della concorrenza sleale, (Milano, Giuffrè).

Guglielmett, Giannantonio (1970): La Concorrenza e i Consorzi (Torino, Unione Tipografica - Editrice Torinense).

JaeGer, Pier Giusto (1971): "I soggetti della concorrenza sleale", en: Rivista di diritto industriale, (I,1971), pp.I, pp. 169-290.

KÖHLER, Helmut (2011): "§ 2 I Nr 1", en: Bornkamm, Joachin et al., Gesetz gegen den unlauteren Wettbewerb, $29^{\mathrm{a}}$ edic. (München, Beck), pp. 137-163.

LIBERTINI, Mario (2016): Lezione di diritto industriale, (Napoli, Edizioni Scientifiche Italiane).

Marco Cos, José Manuel (2009): "Artículo 3. Ámbito subjetivo", en: Fernando Martínez Sanz, Comentario práctico a la Ley de Competencia Desleal (Madrid, Tecnos), pp. 39-53. 
Massaguer Fuentes, José (1999): Comentarios a la ley de competencia desleal (Madrid, Civitas).

Massaguer FuenteS, José (1997): “La acción de competencia desleal en el Derecho español", en: Revista de Derecho Themis (36,1997), pp. 103-118.

Muerza Esparza, Julio: Aspectos procesales de las Acciones de Cesación y Prohibición de Daños en el Ámbito del Derecho Industrial y de la Competencia (Barcelona, Cedecs).

Otero Lastres, José Manuel (1991): "La nueva ley sobre competencia desleal", en: Actas de Derecho Industrial (14, 1991), pp. 25-48.

Perdices Huetos, Antonio (1999): "Comentario a sentencia del Tribunal Supremo, de 15 de abril de 1998", en: Cuadernos Civitas de jurisprudencia civil (50, 1999), pp. 477-496.

Perdices Huetos, Antonio (1996): "Comentario a sentencia del Tribunal Supremo, de 20 de marzo de 1996", en: Cuadernos Civitas de jurisprudencia civil (42, 1996), pp. 909-928.

Poblete Iturrate, Orlando (2007): "El proceso civil de competencia desleal", en: Marco Antonio González Iturra, Competencia desleal: análisis crítico y elementos para la aplicación de la Ley № 20.169, de 2007 (Santiago, Universidad de los Andes), pp. 95-134.

Reveco Urzúa, Ricardo y Padilla Parot, Ricardo (2014): "La competencia desleal en el contrato de distribución de productos. Corte de Apelaciones de Santiago, 13 de marzo de 2014, rol No 6256-2012", en: Revista Chilena de Derecho Privado (22, 2014), pp. 355-363.

Rovelu, Roberto (1967): La concorrenza sleale ed i beni inmateriali di diritto industriale (Torino, Unione Tipografica - Editrice Torinense).

Ruвí Puig, Antoni (2005): "Competencia desleal y libertad de expresión", en: InDret (3, 2005). Disponible en: http://www.indret.com/pdf/291_es.pdf [visitado el 30/12/2016].

SCHRICKER, Gerhard (1968): La repressione della concorrenza sleale negli Stati membri della Comunita Economica Europea. V. V. Italia, (Milano, Dott A. Giuffrè).

SCIRÉ, Francesco (1989): La concorrenza sleale nella giurisprudenza, $2^{a}$ edic., (Milano,Giuffrè), tomo I.

SIGNORINI, Claudia (2014): "Concorrenza sleale e pratiche commerciali scorrette", en: Gustavo Ghidini y Giovanni Cavani, Lezioni di diritto industriale (Milano, Giuffrè), pp. 111-146. 
Suñol LuCEA, Aurea (2012): "Los elementos estructurales que definen la conducta sometida a la Ley de competencia desleal", en: Revista de Derecho Mercantil (284, 2012), pp. 181-226.

Tapia RodríGuez, Mauricio (2008): "Regulación de las relaciones comerciales entre proveedores y distribuidores". Disponible en www.microjuris, bajo la cita: MJD306 [visitado el 30/12/2016].

Tapia Rodríguez, Mauricio "Responsabilidad civil por actos de competencia desleal en el Derecho chileno", en: Marco Antonio González Iturra, Competencia desleal: análisis crítico y elementos para la aplicación de la Ley № 20.169, de 2007 (Santiago, Universidad de los Andes), pp. 85-93.

Tato Plaza, Anxo et al. (2010): La reforma de la Ley de competencia desleal (Madrid, La Ley).

UberTAZZI, Luigi Carlo (2007): Commentario breve alle leggi su proprietà inteIlettuale e concorrenza, $5^{\text {a }}$ edic., (Padova, Cedam).

Vanzettı, Adriano y Dı Cataldo, Vincenzo (2005): Manuale di diritto industriale, $5^{\mathrm{a}}$ edic., (Milano,Giuffrè).

Zabaleta DíAz, Marta (2002): La explotación de una situación de dependencia económica como supuesto de competencia desleal (Madrid, Marcial Pons).

NORMAS JURÍDICAS CITADAS

Ley No 20.169, de 16 de febrero de 2007, regula la competencia desleal (Chile). Ley 3/1991, de enero de 1991, competencia desleal (España).

Codice Civile (Italia).

\section{JURISPRUDENCIA CITADA}

L'Oreal con Laboratorios Prater S.A (2016): Corte Suprema 21 de noviembre de 2016 (acción de competencia desleal) en: Base de datos del Poder Judicial, bajo el rol No C-15897-2015.

Artel S.A.I.C. con Dimeiggs S.A. (2016): Corte Suprema 12 de julio de 2016 (acción de competencia desleal) en: Base de datos del Poder Judicial, bajo rol No C-28421-2016.

Artel S.A.I.C. con Dimeiggs S.A. (2016): Corte de Apelaciones de Santiago 14 de abril de 2016 (acción de competencia desleal) en: Base de datos del Poder Judicial, bajo el rol N ${ }^{\circ} \mathrm{C}-10011-2015$.

Parfums Christian Dior con Garmont Perfumes S.A. y García Herranz, Fernando Eduardo (2015): Corte Suprema 25 de noviembre de 2015 (acción de 
competencia desleal) en: Base de datos del Poder Judicial, bajo el rol $\mathrm{N}^{\circ} \mathrm{C}-23680-2014$.

Artel S.A.I.C. con Dimeiggs S.A. (2015): $22^{\circ}$ Juzgado Civil de Santiago 17 de julio de 2015 (acción de competencia desleal) en: Base de datos del Poder Judicial, bajo el rol No C-21140-2014.

Laboratorios Garden House Chile S.A. con Heriberto Lorenzo Madrid Maulen Comercializadora E.I.R.L. y Apícola y Comercial Colmenares Gasson Ltda (2015): 11 Juzgado Civil de Santiago 26 de junio de 2015 (acción de competencia desleal) en: Base de datos del Poder Judicial, bajo el rol $\mathrm{N}^{\circ} \mathrm{C}-11201-2009$.

Maquival Chile Ltda. con Eserma S.A. (2015): Corte de Apelaciones de Concepción 16 de abril de 2015 (acción de competencia desleal) en: Base de datos del Poder Judicial, bajo el rol No C-547-2014.

Reial Automobil Club de Catalunya, RACC (España) y AC Club Asistencia Limitada (Automóvil Club de Chile) con Andrés Patricio de la Barra Gutiérrez (2015): $22^{\circ}$ Juzgado Civil de Santiago 25 de febrero de 2015 (acción de competencia desleal) en: Base de datos del Poder Judicial, bajo el rol $\mathrm{N}^{\circ} \mathrm{C}-15271-2010$.

Guzmán y Compañía limitada con Estudio Guzmán Limitada (2015): $24^{\circ}$ Juzgado Civil de Santiago 29 de enero de 2015 (acción de competencia desleal) en: Base de datos del Poder Judicial, bajo el rol № C-1660-2012.

Sociedad Comercial Galdames y Garay Limitada con Fernando Galdames Espina (2014): Corte de Apelaciones de Talca 11 de noviembre de 2014 (acción de competencia desleal) en: Base de datos del Poder Judicial, bajo el rol $\mathrm{N}^{\circ} \mathrm{C}-956-2014$.

Preuniversitario Pedro de Valdivia con Establecimientos Educacionales Laej Ltda. (2014): Corte de Apelaciones de Santiago 29 de julio de 2014 (acción de competencia desleal) en: Base de datos del Poder Judicial, bajo el rol $\mathrm{N}^{\circ}$ C-7334-2013.

El Postino S.A. con Encina Tapia Daniel, Geoglobal Spa y Vilches Díaz, Víctor (2014): Corte de Apelaciones de Santiago 30 de mayo de 2014 (acción de competencia desleal) en: Base de datos del Poder Judicial, bajo el rol $\mathrm{N}^{\circ} \mathrm{C}-1604-2013$.

Sociedad Comercial Galdames y Garay Limitada con Fernando Galdames Espina (2014): $2^{\circ}$ Juzgado de Curicó 15 de abril de 2014 (acción de competencia desleal) en: Base de datos del Poder Judicial, bajo el rol Nº C-3564-2011. 
Inversiones Las Marías con MB Mega Brokers Chile S.A. (2013): Corte de Apelaciones de Santiago 16 de diciembre de 2013 (acción de competencia desleal) en: Base de datos del Poder Judicial, bajo el rol № C-3112-2012.

Patricio Rojas Olmedo con Lexis-Nexis Chile Limitada y Alejandro Vergara Blanco (2012): Corte Suprema 7 de diciembre de 2012 (acción de competencia desleal) en: Base de datos del Poder Judicial, bajo el rol № C-8120-2010.

Zip Inversiones y Propiedades SpA con María Antonieta Rabí Ríos (2012):22 Juzgado Civil de Santiago 25 de octubre de 2012 (acción de competencia desleal) en: Base de datos del Poder Judicial, bajo el rol № C-4224-2011.

Sociedad Metalúrgica Quiñones Farfán Ltda. con Tresmontes Lucchetti S.A. (2012): 30 Juzgado Civil de Santiago 14 de marzo de 2012 (acción de competencia desleal) en: Base de datos del Poder Judicial, bajo el rol $\mathrm{N}^{\circ} \mathrm{C}-12225-2010$.

Colegio de Ópticos y Optómetras de Chile A.G. con la Sociedad Chilena de Oftalmología (2011): $8^{\circ}$ Juzgado Civil de Santiago 8 de julio de 2011 (acción competencia desleal) en: Base de datos del Poder Judicial, bajo el rol $\mathrm{N}^{\circ} \mathrm{C}-22629-2010$.

Fundación Cultural Las Condes con Embotelladora del Sur S.A. y Aguas del Sur S.A. (2009): $5^{\circ}$ Juzgado Civil de Santiago 17 de agosto de 2009 (acción competencia desleal) en: Base de datos del Poder Judicial, bajo el rol $\mathrm{N}^{\circ} \mathrm{C}-22094-2007$.

Parque de Concepción S. A. con Inmobiliaria San Pedro (2009): $13^{\circ}$ Juzgado Civil de Santiago 11 de agosto de 2009 (acción de competencia desleal) en: Base de datos del Poder Judicial, bajo el rol N ${ }^{\circ} \mathrm{C}-11487-2008$.

Patricio Rojas Olmedo con Lexis-Nexis Chile Limitada y Alejandro Vergara Blanco (2009): 26º Juzgado Civil de Santiago 15 de junio de 2009 (acción de competencia desleal) en: Base de datos del Poder Judicial, bajo el rol $\mathrm{N}^{\circ} \mathrm{C}-3266-2008$.

España: STS, 25.07.2007 en: Base de datos Westlaw España, bajo el código RJ 2007, 4705.

España: SAP de Barcelona, 4.07.2007 en: Base de datos Westlaw España, bajo el código JUR 2007, 295133.

España: AAP de Madrid, 29.05.2007 en: Base de datos Westlaw España, bajo el código JUR 2007\321899.

España: SAP de Madrid, 5.06.2006 en: Base de datos Westlaw España, bajo el código AC 2007/277. 
España: STS, 3.02.2005 en: Base de datos Westlaw España, bajo el código RJ $2005 \backslash 1458$.

España: SAP de Madrid, 4.06.2004 en: Base de datos Westlaw España, bajo el código (AC 2004, 1723).

España: STS, 6.02.2001 en: Base de datos Westlaw España, bajo el código RJ 2001, 543.

España: STS, 15.04.1998 en: Base de datos Westlaw España, bajo el código RJ 1998, 2053.

España: SAP de Sevilla, 28.01.1998 en: Base de datos Westlaw España, bajo el código AC 1998, 290.

Francia: Com., 30.01.1996, Fleurs Éclaris (SA) c. Office Néerlandais des ProduitsLaitiers en: Base de datos LawLex Francia, bajo el código No 00573N70CD. 